\title{
Variables associated with the modalities of psychic adaptation (coping mechanisms and psychic defense mechanisms) in depressive disorders
}

\author{
Dănuț Ioan Craşovan ${ }^{\mathrm{a} *}$, Laura Patricia Farcaş ${ }^{\mathrm{b}}$ \\ ${ }^{a}$ Babeș-Bolyai University (UBB University Center in Reșița), 320085 Resita, Traian Vuia Square, \\ No. 1 - 4, Caras-Severin District, România, https://uem.ro/ \\ ${ }^{b}$ SPER Institute, Splaiul Independentei, No. 17, Bucharest, România.
}

\begin{abstract}
The study lists a series of research on the particularities of psychic adaptation in depressive disorders, respectively psychological defense mechanism and coping mechanisms. At the same time, the study analyzes the existing relationships, in depressive disorders case, between coping and variables such as tools and the methodology for assessing the coping process, the relevance and usefulness of the coping process in the clinic and the treatment of psychopathology as information processing, the personality and typology of the human subject, the type of disorder diagnosed, age of the human subject, locus of control, parental style, life events, personal experience, adherence to medication, gender, economic situation, profession, culture/environment, presence or absence of depressive disorders.
\end{abstract}

Keywords: depressive disorders; psychic adaptation; coping mechanisms; psychic defense mechanisms

\section{Mental adjustment features in major depressive disorders}

Currently, major depressive disorders make a substantial contribution to the global burden of the disease worldwide by incurring high costs for health care (König, König \& Konnopka, 2020; Lépine, Briley, 2011; World Health Organization, 2011) and by the fact that depression, in its various forms or associations with other chronic physical diseases, will be until 2030 the main cause of disabilities. (Moussavi, Chatterji, Verdes, et al., 2007).

In this context, of the evolution of major depressive disorders and the associated costs, the psychic adaptation modalities such as coping mechanisms may be an important general mechanism of change in the psychotherapy of depressive disorders (Starrs, Perry, 2018). At the same time, the increased interest for the analysis of psychic defense is also determined by the extent of depression (Stiemerling, 2006), affecting all age groups and social environment.

Thus, by identifying the role of psychic defense mechanisms used by human subjects in major depressive disorder, psychotherapeutic intervention, recovery and prevention can be made more efficient in terms of time and cost.

The identification of the specific, and the adaptive level of the psychic defense, is an important factor in the intervention (psychotherapy or medication), with a significant relationship between the intervention and the efficiency of the intervention mediated by the defensive particularities of the defense of the human subjects.

* Corresponding author.

E-mail address: d.crasovan@uem.ro

DOI: $10.51865 / J E S P .2021 .1 .21$ 


\section{Psychic defense mechanisms features in depressive disorders}

Despite a long history (Crasovan, 2019, 2020; Vaillant, 2012) the concept and technique of psychological defense analysis is a current working technique both in psychopathological clinic and other fields of psychology (Ionescu, Jacquet, Lhote, 2002), the lists of classification, inventory and the number of psychological defense mechanisms shows a continuing concern for this psychoanalytical concept (Crasovan, 2019, 2020; Ionescu, Jacquet, Lhote, 2002).

Clinical studies indicate that patients with depressive disorders use some defenses with low range of adaptability, therefore recovering from these disorders requires identifying and improving the ways of mental adjustment (Akkerman, Lewin Carr, 1999; Kneepkens, Oakly, 1996; DeFife, Hilsenroth, 2005).

It is known that there is a specific defensive functioning for each psychopathological condition, in fact an association of defensive mechanisms (Blackman, 2009). Therefore, depressive and anxious patients differ from other psychopathological conditions (and from subjects without a psychiatric history) in the level of defensive functioning, they predominantly use projection, a fact demonstrated by Blaya, Dornelles, Blaya, Kipper, Heldt, Isolan, Bond, Manfro (2006), the results of this study pleading for the development of specific psychotherapeutic interventions.

In this context, of the role of psychic defense mechanisms in depressive disorders, a series of recent studies suggest the predictive value that defensive styles and levels can have in the planning and success of therapeutic strategies (in the case of shortterm psychotherapeutic treatments) both in the case of major drepressive disorder (Van, Dekker, Penn, Abraham, Schoevers, 2009) as well as for the general population, where the maturity of defenses is an effective predictor for indicating the level of mental health and ensures good social functioning with lower costs in health care (Vaillant, 1993 a; Vaillant, 1993 b; MacGregor, Davidson, Rowan, Barksdale, Maclean, 2003) .

Hoglend and Perry (1998) investigated the predictive capacity of the level of defensive functionality in major depressive disorder and the results of the study highlights the mediating low and high effect of the adaptive psychic defenses in the evolution of the major depression, the high adaptive level of the defenses being obviously in the patients with significant improvement in the evolution of depressive disorder. Another study (Porcerelli, Olson, Presniak, Markova, Miller, 2009), focused on the functioning of psychic defense in major depression (performed on African American women) emphasizes the use of "medium level" defensive mechanisms, such as mental inhibition, minor image distortion, major image distortion, dissociation, isolation and devaluation.

Another aspect highlighted by Vaillant (1993 b), based on the data obtained from the Study of adult development, shows the existence of significant correlations between the state of mental health and the maturity of the defenses (correlation independent of the level of education, gender and social class of the participants). Thus, defenses (1) "generally" mature (having adaptive character) were registered in $9 \%$ of the participants (male) with pronounced depression and in 61\% of the participants (male) without psychiatric history and defenses (2) "currently" mature were identified in $47 \%$ of the male participants diagnosed with depression and in $7 \%$ of the male participants without a psychiatric history (Vaillant, 1993 b). Vaillant (2000) observed that the sudden changes in both internal and external world causes conflict and cognitive dissonance, defenses mechanisms having the role to reduce them. Without them, these sudden changes result in anxiety and/or depression.

Another study (Plutchik, 1991 in Ionescu, Jacquet, Lhote, 2002) conducted on participants diagnosed with major depressive disorder without psychotic elements, according to DSM IV R criteria, to which the Lifestyle Index was applied, shows the existence of higher scores for the reactional formation, projection, regression, repression and, in general, a significant increase in mental defense compared to participants who are not diagnosed with mental illness (Crașovan, 2011). These 
results are in agreement with the results of other studies (Bond, Gardner, Christian, Sigal, 1983; Plutchik et al., 1979, Vaillant et al., 1986, Wong, 1989 in Ionescu, Jacquet, Lhote, 2002) that highlight the use of the depressive participants of two categories of defenses of the type of primitive or immature defenses (regression, projection) and intermediate or neurotic defenses (reaction formation, repression) and, at the same time, an increase in the intensity of defense of depressive participants compared to participants who are not diagnosed with disorders or mental illness.

Another study by Flett, Besser and Hewitt (2005) on the association between defense and depression styles, in fact on the relationship between perfectionism, defense and depression styles, shows a comparison between two methods of assessing mental defense: (1) self-report method (DSQ-40) and (2) the evaluations of an observer (a person close to the participant), at the same time evaluating perfectionism and depression. From the analysis of the results it was found that the existence of the association of perfectionism socially prescribed with depression in both modes of evolution (DSQ-40 and observer) and the existence of an association of perfectionism (regardless of orientation) with depression (based on the evaluation made by the observer). At the same time, it was found in both evaluation variants that the prescribed social perfectionism is associated with the immature defense style and with the neurotic defense style. The results of the study by Flett, Besser and Hewitt (2005) are in agreement with the results of other studies conducted by Kennedy, Schwab, Hide (2001) and Kwon, Lemon (2000), these last two studies indicate the existence of an association between depression and immature, neurotic defenses, also known that recovery from depression is also due to the transition from immature defenses to mature defenses (Akkerman, Lewin, Carr, 1999).

Regarding the efficacy of one type or another of treatment in the case of depression (psychotherapy or antidepressant medication or the existing relationship between psychotherapy and antidepressant medication) in the context in which an important part of the psychotherapeutic results is based on understanding the defensive particularities of the patients (Bond, 2004), some authors (Mullen, Blanco, Voughn, Roose, 1999) have highlighted a series of defenses that reduce the effectiveness of prescribed antidepressant medication, with studies with different results, but in which the treatment constitutes psychotherapy (Hoglend, Perry, 1998; Bond, 2004; Hersoug, Sexton, Holglend, 2002).

Another study conducted by Bond and Perry (2004) on the results of long-term psychotherapeutic intervention of psychodynamic perspective on the defensive style in personality disorders, depression and anxiety, highlights an improvement in the level of mental defense and the analysis of the results shows significant changes in the levels of defense (evaluated with Defensive Style Ouestionnaire-40), the participants showing an increase in adaptability and flexibility during the psychotherapeutic intervention (compared to the initial moments of the intervention). At the same time, it was observed that improving the defensive style of the participants caused changes at the symptomatic level without establishing the causes of the change and improving the psychotherapeutic relationship. The study conducted by Bond and Perry (2004) had a number of limitations, with therapists not adhering to standard psychodynamic treatment, some subjects followed another treatment concomitantly with psychotherapeutic intervention (medication), the absence of the control group.

Regarding the specificity of psychic defense in depressive disorders, Blackman (2009) includes specific defenses in the category of depression- disidentification, reaction formation, identification with the subject, identification with the lost object, return against one's own person, passivity and repression, depression being considered as an association between the depressive affect and the specific defenses by which the human subject tries to manage the affect perceived by the subject's ego as a danger.

From the psychoanalytic point of view (Nasio, 1999) in the depressive functioning a major importance has (1) the integrity of the ego, its functions (for the serious impairment of these functions the depression takes on the psychic "valances"), (2) the force of the ego (between depressive affect and tolerance to affect there is an inverse relationship, the increasing of the intensity of depressive affect decreases tolerance to affect) and (3) the level of functionality in the relation of the subject with affective 
invested "objects" (depressive affect causing a decrease in intensity that can reach up to definitive withdrawal of the subject from the relationship).

In conclusion, from the analysis of the studies presented it can be observed the existence of a specific psychic adaptation in depression, consisting of the use of the following defensive modalities: deidentification, reaction formation, idealization (Irimia, 2003), passive aggression, projection, dissociation, withdrawal and acting out (Craşovan, 2011), which shows the existence of a medium adaptive level defense.

Another conclusion, resulting from longitudinal studies on depressive participants and participants without a psychiatric past (Vaillant, $1993 \mathrm{a}, \mathrm{b}$ ), shows the existence of a significant correlation between the mental health and the maturity or the adaptive level of the defense, the defense level having the role of mediating factor in the recovery and prevention of relapse. Therefore, the use by the subjects of mature defenses with high adaptive level represents a good predictor for the state of mental health, and even of physical health, in the future (Vaillant, $1993 \mathrm{a}, \mathrm{b}$ ). This aspect can also be correlated with the importance of ,maturing" of the defense, the transition from immature defenses to mature defenses being an important factor that allows the recovery from depression (Ionescu, Jacquet, Lhote, 2002).

\section{Particularities of coping mechanisms in depressive disorders}

The particularities of psychic adaptation in depressive disorders are addressed both from the point of view of psychic defense mechanisms and from the point of view of coping mechanisms, the two adaptive modalities of the human subject representing after some authors two independent modes of psychic adaptation, coping and defenses are facets of common adaptation processes (Maricutoiu, Crasovan, 2016).

About the triggers for depressive disorders, some authors (Ellicott, Hammen, Gitlin, Brown, Jamison, 1990; Rudolp, Hammen, Burger, 2000) argue that stress, in this case, psychosocial stress, may be a risk factor and at the same time, a trigger factor for depression, provided that not all people exposed to stress develop depressive or affective disorders (Kessler, 1997).

Following these findings, the question arose: why only some human subjects develop affective disorders following stressful life events, while others do not? The possible answer to this question is given by the way the following factors are correlated: personality type, genetic inheritance, previous life experience, parental style, social network and coping strategies through which the human subject copes with stress and gender, psychiatric history of subjects and probably other factors that are not currently linked to depressive disorders. Analyzing these factors, the relationship between them and coping strategies in subjects diagnosed with depressive disorders, will be able to explain why only some human subjects develop affective disorders (depressive disorders), and others not in the conditions in which stress is present in everyone's life.

Thus, when coping strategies fail or are not adequate, adaptive, stress can lead to physical and mental illness. People who face stress through effective coping strategies are more appropriate and without psychological problems. From this point of view, of the efficiency of coping mechanisms, we distinguish effective strategies, by which the human subject is involved in solving the stress-generating problems, in seeking information and trying to change the situation and avoidance strategies (through which the human subject avoids the stress situation through denial, delusions and withdrawal/avoidance of the stress-generating situation) or through the emotional nature, involving emotional responses (whereby human subjects self-accuse themselves of being too emotional, which is why they become angry or tense) or ruminating answers, consisting of behaviors or thoughts focused on depressive symptomatology and the causes of the disease (Suls, Fletcher, 1985) self-oriented, associated with the presence of stress and low efficiency (Folkman, Lazarus, 1988) or lack of efficiency/adaptability. 
Lately, a number of researchers (Sommerfield, McCrae, 2000; Lazarus, 2000) have drawn attention to the relationship between coping and depression, an obviously fact in the context of changing treatment methods for depressive disorders by introducing cognitive behavioral psychotherapy (David, 2006 and interpersonal psychotherapy, the style/coping strategies becoming one of the important goals of the treatment. From this point of view, Walker, Lindner, Noonan (2009) show that the relationship between depression and coping style may be a better predictor for the evolution and severity of depression.

Taylor and Stanton (2007) who show the impact of coping on mental and physical health, consider optimism, self-control, self-esteem and social support as resources in the coping process, the origin of these resources of the coping process being at the hereditary level, at the level of the interactions between heredity and the environment, at the level of the early life experiences, even at the neuronal level, all these aspects give another perspective in order to optimize the interventions on the coping process.

Analysis of some research on coping strategies in major depressive disorder, and depression in general (Schussler, Grischke, Ruger, 1992; Sherbourne, Hayes, Wells, 1995; Dekker, Ormel, 1999; Schouws, Dekker, Tuynman-Qua, Kwakman, Jonghe, 2001; Uehara, Sakado, Sato, Takizawa, 2002; McWilliams, Cox, Enns, 2003; Yamada, Nagayama, Tsutiama, Kitamura, Furukawa, 2003) led to the following findings: the existence of difficulties in distinguishing between depressive symptoms and coping or adapting behaviors (Schussler, Grischke, Ruger, 1992); the presence of a better clinical depression evolution is associated with the active coping style (Sherbourne, Hayes, Wells, 1995); most depressive patients use passive and avoidant coping, significantly more frequently than patients with lower depression, and passive coping is the most consistent predictor of high depression scores (Dekker, Ormel, 1999; Schouws, Dekker, Tuynman-Qua, Kwakman, Jonghe (2001) show that active approach and seeking social support are associated with better quality of life and avoidance is associated with increased depression severity, however, the study does not reveal gender differences in terms of coping strategies/style; Uehara, Sakado, Sato, Takizawa (2002) argue that problem-oriented coping style is influenced by depression, whereas emotion-oriented coping style is influenced by anxiety; problemoriented coping style and social-relationship coping style are negatively correlated, and emotion-oriented coping style is positively associated with high scores for depression and anxiety (McWilliams, Cox, Enns, 2003); patients with good outcomes after 6 months used significantly more rumination while patients with poor outcomes used significantly more dangerous activities (Yamada, Nagayama, Tsutiama, Kitamura, Furukawa, 2003).

Coping style identification has a dual clinical utility. First, the identification of the coping style will allow the course of the development of the emotional disorder to be improved by eliminating non-adaptive coping strategies and, secondly, identifying coping strategies may play a preventive role in populations at risk of developing affective disorders (Kessing, Agerbo, Mortensen, 2004).

As can be seen, there is a gap between the theory and the clinical utility of the coping process, as well as some contradictions, there is a need to clarify the existing relationships between coping and variables such as: the tools and methodology for evaluating the coping process (Crasovan, $2014 \mathrm{a}$ ), the relevance and usefulness of the coping process in the clinic and the treatment of psychopathology as information processing (David, 2006), the personality and the typology of the personality of the human subject (Baltrusch, Stangel, Titze, 2007; Bloch, Chemama, Depret, Gallo, Leconte, Le Ny, Postel, Reuchlin, 2006; Carver, Connor-Smith, 2010; Coyne, Gottlieb, 1996; Denollet, 1998; Denollet, 2005; Denollet, Perdersen, Ong, Erdman, Serruys, van Domburg, 2006; Denollet, Sys, Brutsaert, 1995; Habra, Linden, Anderson, Weinberg, 2003; Pedersen, Middel, 2005; Schiffer, Pedersen, Widdershoven, Hendriks, Winter, Denollet, 2005; Moos, Holahan, 2003; Suls, David şi Harvey, 1996), type of disorder diagnosed (Blackman, 2009; Craşovan, 2013), age of the human subject (Christensen, Kessing, 2005; Skinner şi Zimmer-Gembeck, 2007), locus of control (Bjørkløf, Engedal, Selbæk, Maia, Coutinho \& Helvik, 2016), parental style (Uehara, Sakado, Sato, Someya, 1999), life events (Craşovan, Tomici, 
2014; Kessing, Agerbo, Mortensen, 2004; Kessler, 1997; McNaughton, Patterson, Irwin, Grant, 1992; Parker, Brown, 1982; Ravindran, Matheson, Griffiths, Merali, Anisman, 2002; Rosenberg, Peterson, Hayes, 1987; Sherbourne, Hayes, Wells, 1995; Szadoczky, Rozsa, Zambori, Furedi, 2004; Vaillant, 1993 b), personal experience (Onisei, Dumitru, Trifu, 2020; Vaillant, 1993 b), medication adherence (Greenhause, Meyer, Johnson, 2000; Lyubomirsky, Nolen-Hoeksema, 1995; Nolen-Hoeksema, 1991; Nolen-Hoeksema, Larson, 1999; Nolen-Hoeksema, Morrow, 1991; Schuman, Lenz, Berghöfer, Müller-Oerlinghausen, 1999; Wong, Lam, 1999), gender (Angst, Gamma, Gastpar, Lépine, Mendlewicz, Tylee, 2000; Arora \& Dhillon, 2017; Billings, Moos, 1984; Craşovan, 2014; Crașovan, 2015; Dekker, Ormel, 1999; Folkman și Lazarus, 1988; Galanakis, Stalikas, Kalia, Karagianni, Karela, 2009; Hoffart, Martinsen, 1993; Lam, Scuck, Smith, Farmer, Checkley, 2003; Nolen-Hoeksema, 1987; Piccinelli, Wilkinson, 2000; Schouws, Dekker, Tuynman-Qua, Kwakman, Jonghe, 2001; Vaillant, 1993 b; Wilhelm, Parker, 1993; Wong și Power, 2019), economic situation (Vaillant, 1993 b), profession (Vaillant, 1993 a), culture/ environment (Crasovan, 2009; Ionescu, 2000; Stan, Drăgoi, Costea, 2020), presence or absence of depressive disorders (McWilliams, Cox, Enns, 2003; Cosway, Endler, Sadler, Deary, 2000; Saklofske, Kelly, 1995).

The reaction to stress is mediated by the personality of the human subject's lifestyle. The importance of personality, personality traits that mediate coping style or strategies is significant. Personality and coping processes both separately and interactively play a role in influencing physical and mental health, some research directions in personality psychology being focused on coping modalities of the human subject in relation with stress (Carver, Connor-Smith, 2010). Thus, coping strategies are closely related to the method of adaptation (Moos, Holahan, 2003), to the type of cognitive, behavioral or emotional response and to the approach of personality as a state or trait, although, within the process of adaptation, the coping mechanisms are considered as responses to stress-generating situations or to current perceived stress and not stable characteristics / personality traits (Coyne, Gottlieb, 1996).

Suls, David şi Harvey (1996) present a retrospective on the psychological studies on the coping process of stress, identifying three generations from the theoretical point of view and from the point of view of process research: (a) psychoanalysis and the school of ego development, with the tendency to equate personality with coping strategies; (b) the transactional approach, which emerged in the 1960s, which underlines the situational and cognitive influences of the coping process, minimizing the role of individual differences, and recently (c) the third generation, focusing on the role of personality in the coping process, maintaining, in the same time and operational distinctions at the level of personality, asessment and adaptation.

Thus, the coping strategies of the subject are mediated by his personality, by the personality type, the behavior type, or of the type A personality (Bloch et al., 2006), type B personality (Alsomali, Osman \& Alzahrani, 2017), type C personality (Baltrusch, Stangel, Titze, 2007) and type D personality (Denollet, 1998; Denollet, 2005; Denollet, Perdersen, Ong, Erdman, Serruys, van Domburg, 2006; Denollet, Sys, Brutsaert, 1995; Habra, Linden, Anderson, Weinberg, 2003; Pedersen, Middel, 2005; Schiffer, Pedersen, Widdershoven, Hendriks, Winter, Denollet, 2005).

Regarding parental style a study conducted by Uehara, Sakado, Sato, Someya (1999) on participants with major depressive disorders in remission, shows a possible relationship between parental styles and individual coping skills of children in relation to perceved stress.

From the point of view of the relationship between coping and medication adherence in affective disorders, or a series of authors believe that the efficiency of the depressive disorder depends on factors such as respect for medication, depression comorbidity, coping modalities, residual symptomatology, economic situation of patients (Schuman, Lenz, Berghöfer, Müller-Oerlinghausen, 1999) or social support (Nolen-Hoeksema, 1991; Nolen-Hoeksema, Morrow, 1991; Nolen-Hoeksema, Larson, 1999; Lyubomirsky, Nolen-Hoeksema, 1995). Timely identification of these factors at the beginning of treatment can increase adherence and efficency of 
treatment and the chances of recovery or improvement (Greenhause, Meyer, Johnson, 2000). It is also important in the case of the affective disorders, from the point of view of the therapeutic efficiency (medication or psychotherapy), the identification of coping strategies, in particular of non-adaptive coping strategies and the modification of a strategy or the replacement of the adaptive, effective coping strategies (Wong, Lam, 1999). In this regard, it is considered important to respect the therapeutic intervention, either of a medication or psychotherapeutic nature, or the combination of the two types of intervention but with the increase in focus on psychotherapy, while offering support for patients in learning new coping strategies with high livel of adaptation.

Analysing the relationship between coping and age, despite the conducted studies, is not identified, yet, a clear relationship between these two variables, respectively between coping and age, beacuse the studies were performed over wide intervals of age and with several methodologies (Christensen, Kessing, 2005).

As for age group coping strategies, studies on developmental differences and possible modifications are difficult to integrate. Thus, recent relative research (Skinner şi Zimmer-Gembeck, 2007) on coping strategies in childwhood and adolescence show that these strategies are focused on how children deal with stressors in real life contexts, by analyzing the link between emotional development, attention, behavioral self-regulation, constitution and social factors.

A longitudinal study conducted by Aldwin, Sutton, Chiara \&Spir, (1996) assessing the action of stress and coping modalities identified the existence of a significant overall effect of age on coping strategies, being identified strategies such as instrumental actions, cognitive restructuring, social support and hostility, the use of these strategies decreasing concomitantly with increasing age.

In a research conducted on a non-clinical sample (Steiner, Erickson, Hernandez, Pavelski, 2002) it is showed that the style of coping in early and middle adolescence seems to be associated with the state of health, the coping style becoming a potential indicator of health. Analyzing the relationship between coping and the presence or absence of depressive disorder conducted by McWilliams, Cox, Enns (2003), Cosway, Endler, Sadler, Deary (2000) and Saklofske, Kelly (1995) both on depressive clinical population (McWilliams, Cox, Enns, 2003) and on the general population (Cosway, Endler, Sadler, Deary, 2000; Saklofske, Kelly, 1995 have shown that coping strategies with low efficency (coping with emotion) are associated with depression in contrast to the highly adaptable effective coping strategies (behavioral or cognitive coping) which are not associated with mental illness, at least not depression.

Currently, the existence of a possible interaction between individual vulnerability, coping strategy, life events and the risk of developing depression is accepted. Most studies have found that there is a substantial, and partially causal relationship between life events and depression (Kessing, Agerbo, Mortensen, 2004) or shows an increased risk for developing a depressive episode after major life events (Kessler, 1997). For these reasons, a series of studies conducted by different authors (McNaughton, Patterson, Irwin, Grant, 1992; Parker, Brown, 1982; Ravindran, Matheson, Griffiths, Merali, Anisman, 2002; Rosenberg, Peterson, Hayes, 1987; Sherbourne, Hayes, Wells, 1995; Szadoczky, Rozsa, Zambori, Furedi, 2004) evaluated the impact of life events on the emergence and development of depressive disorders.

Regarding the relationship between coping and the gender of subjects Wong şi Power (2019) following a longitudinal study on the possible association between Chinese children coping strategies and depressive symptoms in the context of school transition, it identifies three coping strategies specific to this period, respectively, negative coping, positive coping and distraction, as well as some differences between boys and girls regarding the relationship between coping and depressive symptoms.

Concerning the gender differences regarding defensive functioning in the case of major depressive disorder, under short-term supportive psychodynamic psychotherapeutic treatment, some research has suggested that the level of psychic defense is influenced differently by this type of disorder (Van et al., 2009) does not show individual differences in the overall level of defense maturity, but different 
defensive assemblages, specific to the two genres, have been observed (Cramer, 1991; Watson, Sinha, 1998), explained by the different socialization modalities that favor the appearance and development of some defenses and the absence/inhibition or the low level of functioning of other defenses (Petraglia, Thygesen, Lecours, Drapeau, 2009).

Another recent study (Crașovan, 2015) shows that women coping mechanisms such as mental disengagement, focus on and venting of emotions, religious coping and use of emotional social support are specific, while substance use has been identified as a men's specific coping mechanism. In a research on the perception of stress in the workplace according to gender (Galanakis, Stalikas, Kalia, Karagianni, Karela, 2009) it was found that women have a higher perceived level of stress than men, but when taken in calculating marital status, age and education differences became insignificant.

As a limiting aspect regarding the relation between the gender of the subjects and coping it can be seen that some of the conducted studies were not focused on this relationship (Schouws, Dekker, Tuynman-Qua, Kwakman, Jonghe, 2001; Hoffart, Martinsen, 1993) because they included men and women but unequally, generally more women are included (Christensen, Kessing, 2005). Also, another study conducted by Folkman şi Lazarus (1988), does not highlight differences between the two gender categories in terms of emotional coping modalities.

On the other hand, there are a number of studies that highlight the differences between the two gender categories in terms of coping mechanisms. Thus, a series of studies conducted by different authors (Lam, Scuck, Smith, Farmer, Checkley, 2003; Dekker, Ormel, 1999; Billings, Moos, 1984) reveal the existence of differences between the two genres in terms of the type of coping used, women using emotional coping strategies while men used active coping strategies. Or another study (Arora \& Dhillon, 2017) in which positive reassessment is identified as the only coping strategy in which there are significant gender differences, with women having higher average scores.

From the point of view of the relation between the gender of the subjects, the coping strategies used and the depressive disorders, some authors (Nolen-Hoeksema, 1987) argue that the high vulnerability of women for the development of the depressive disorders is due to the gender differences in the coping strategies used.

The response of women to stress is ruminative, amplifying, as opposed to men whose response is generally behavioral, these results being in agreement with the recent research regarding the differences between the two gender categories regarding the use of coping strategies in depression and which shows that men use coping strategies that involve physical or instrumental activities, while women's coping strategies are less active, these by further analyzing the causes and implications of depression (Piccinelli, Wilkinson, 2000; Wilhelm, Parker, 1993; Angst, Gamma, Gastpar, Lépine, Mendlewicz, Tylee, 2000).

\section{Conclusions}

The psychic adaptation mechanisms, respectively the psychic defense mechanisms and the coping mechanisms, can play a significant role in the prevention and treatment of the depressive disorders, these forms of psychic adaptation can be mechanisms of change in the treatment and prevention of the depressive disorder in the current context regarding the magnitude and the costs associated with these global disorders.

Despite the identification of the specific defensive profile of depressive disorders, this analysis identifies a number of contradictions concerning the relationship between psychic defense mechanism, coping mechanism and some variables such as: tools and the methodology for assessing the coping process, the relevance and usefulness of the coping process in the clinic and treatment of psychopathology as information processing, the personality and typology of the human subject, diagnosis of the type of disorder, age of the human subject, locus of control, parental style, life events, 
personal experience, adherence to medication, gender, economic situation, profession, culture/environment, presence or absence of depressive disorders.

\section{References}

1. Alsomali, N. Y., Osman, A. A. M., \& Alzahrani, K. M. (2017). The comparison between health care providers having personality type (A) versus (B) in using coping strategies in job burnout. Journal of Nursing and Health Science, 6(4), 71-74.

2. Arora, M., \& Dhillon, R. (2017). Perceived Stress, Depression and Coping Strategies in Adolescents: A Gender Perspective. Indian Journal of Community Psychology, 13(1), 149.

3. Akkerman, K., Lewin, T. J., Carr, V. J. (1999). Long-term changes in defense style among patients recovering from major depression. Journal of Nervous and Mental Disease, 187, 8087.

4. Aldwin, C. M., Sutton, K. J., Chiara, G., Spir, A. (1996). Age differences in stress, coping, and appraisal: findings from the normative aging study. J Gerontol, 51, 177-188.

5. Angst, J., Gamma, A., Gastpar, M., Lépine, J. P., Mendlewicz, J., Tylee, A. (2000). Gender differences in depression. Eur Arch Psychiatr Clin Neuroscience, 252, 201-209.

6. Baltrusch, H. J., Stangel, W., Titze, I. (2007). Stress, cancer and immunity. New developments in biopsychosocial and psychoneuroimmunologic research. Immunehematology, Transfusion Medicine, Bloodbank, Hannover Medical University.

7. Billings, A. G., Moos, R. H. (1984). Coping, stress and social resources among adults with unipolar depression. Journal of personality and social psychology, 46, $877-891$.

8. Blackman, J. S. (2009). 101 apărări. Cum se autoprotejează mintea. Editura Trei: Bucureşti.

9. Blaya, C., Dornelles, M., Blaya, R., Kipper, L., Heldt, E., Isolan, L., Bond, M., Manfro, G. G. (2006). Do defense mechanisms vary according to the psychiatric disorder? Revista Brasileira de Psiquiatria, 28 (3), 179-183.

10. Bloch, H., Chemama, R., Depret, E., Gallo, A., Leconte, P., Le Ny J.-F., Postel, J., Reuchlin, M., (coord.). (2006). Marele dicţionar al psihologiei. Bucureşti: Edirura Trei.

11. Bjørkløf, G. H., Engedal, K., Selbæk, G., Maia, D. B., Coutinho, E. S. F., \& Helvik, A. S. (2016). Locus of control and coping strategies in older persons with and without depression. Aging \& mental health, 20(8), 831-839. https://doi.org/10.1080/13607863.2015.1040722

12. Bond, M. (2004). Empirical studies of defense style: Relationships with Ppsychopathology and change. Harvard Review of Psychiatry, 12, 263-278.

13. Bond, M., Gardner, S. T., Christian, J., Sigal, J.-J. (1983). Empirical study of self-rated defense styles. Archives of General Psychiatry, 40, 333-338.

14. Bond, M., Perry, J. C. (2004). Long-term changes in defense styles with psychodynamic psychotherapy for depressive, anxiety, and personality disorders. American Journal of Psychiatry, 161, 1665-1671.

15. Carver C. S., Connor-Smith J. (2010). Personality and Coping. Annual Review of Psychology, 61, 679-704.

16. Christensen, M. V., Kessing, L. V. (2005). Clinical use of coping in affective disorder, a critical review of the literature. Clinical Practice and Epidemiology in Mental Health, 1: 20.; http://www.cpementalhealth.com/content/1/1/20

17. Cosway, R., Endler, N. S., Sadler, A. J., Deary, I. J. (2000). The coping for stressful situations; Factorial structure and associations with personality traits and psychological health. J Applied Biobehav Res, 5, 121-143.

18. Coyne, J. C., Gottlieb, B. H. (1996). The mismeasure of coping by checklist. J Pers, 64, 959991.

19. Cramer, P. (1991). Development of defense mechanisms: Theory, research, and assessment. New York: Springer-Verlag.

20. Craşovan, D. I. (2020). De la Sigmund Freud la DSM IV - Inventarul mecanismelor de apărare psihică (partea a doua)/From Sigmund Freud to DSM IV - inventory of psychological defense mechanisms (the second part). The Romanian Journal of Psychology. Volume 66, No. $1,35-48$.

21. Craşovan, D. I. (2019). De la Sigmund Freud la DSM IV - Inventarul mecanismelor de apărare psihică (partea întâi)/From Sigmund Freud to DSM IV - inventory of psychological defense mechanisms (part one). The Romanian Journal of Psychology. Volume 65, No. 4, 293-309. 
22. Craşovan, D. I. (2015). Gender-related differences in self-reported coping. A study on romanian population. The Romanian Journal of Applied Psychology. Vol. 17, No. 1, 17-22.

23. Craşovan, D. I. (2014 a). Limits of methods used in analysing the psychological defense: psychological defense mechanisms and coping mechanisms. Journal of Educational Sciences \& Psychology, 4(2).

24. Craşovan, D. I. (2014). Gender differences in the context of psychological defense mechanisms - Romanian version of DSQ 60. The Romanian Journal of Psychology. Volume 60, No. 1, pg 60-69.

25. Craşovan, D. I, Tomici, D. (2014). Psychological adaptive mechanisms in homeless people - a study carried out on people in the Caritas Federation Night Shelter, Catholic Diocese Timișoara, România. In Rață, G., and Runcan, P.L. (Eds), Social Issues. Cambridge Scholars Publishing, Newcastle upon Tyne, UK. Cambridge Scholars Publishing. ISBN (10): 1-44385676-2, ISBN (13): 978-1-4438-5676-8, http://www.cambridgescholars.com\&

26. Craşovan, D. I. (2013). The role of defence mechanisms and coping mechanisms in depressive disorders. In P. Runcan, G. Raţă and A. Gavreliuc (Eds.), Applied Social Sciences: Psychology, Physical Education and Social Medicine (pp 11-19), 12 Back Chapman Street, Newcastle upon Tyne, NE6 2XX, UK: Cambridge Scholars Publishing. ISBN (10): 1-44384524-8, ISBN (13): 978-1-4438-4524-3, http://www.cambridgescholars.com\&

27. Craşovan, D. I. (2011). The role of defence mechanisms and coping mechanisms in depression disorders. Unpublished doctoral thesis, University of Bucharest.

28. Craşovan, D. I. (2009). Multicultural approach in interpreting the psychopathological fact. In R. Sassu (Eds.), Modern psychological research - directions and perspectives: current approaches in Applied Psychology (pp 17-22). Bucuresti: Editura Universitara Publishing. ISBN 978-973-749-756-7.

29. David, D. (2006). Tratat de psihotrapii cognitive şi comportamentale. Iaşi: Editura Polirom.

30. DeFife, J. A., Hilsenroth, M. J. (2005). Clinical utility of the Defensive Functioning Scale in the assessment of depression. Journal of Nervous and Mental Disease, 193, 176-182.

31. Dekker, J., Ormel, J. (1999). Depression and coping. Eur J Psychiatry, 13,183-89.

32. Denollet, J. (1998). Personality and risk of cancer in men with coronary heart disease. Psychol Med, 28, 991-995.

33. Denollet, J. (2005). Standard assessment of negative affectivity, social inhibition, and Type D personality. Psychosom Med, 67,89-97.

34. Denollet, J., Perdersen, S. S., Ong, A. T., Erdman, R. A., Serruys, P. W., van Domburg, R. T. (2006). Social inhibition modulates the effect of negative emotions on cardiac prognosis following percutaneous coronary intervention in the drug eluting stent era. Eur Heart J, 27, 171-177.

35. Denollet, J., Sys, S. U., Brutsaert D. L. (1995). Personality and mortality after myocardial infarction. Psychosom Med, 57, 582-591.

36. Ellicott, A., Hammen, C., Gitlin, M., Brown, M., Jamison, K. (1990). Life events and the course of bipolar disorder. Am J Psychiatry, 147, 1194-1198.

37. Flett, G. L., Besser, A., \& Hewitt. (2005). Perfectionism, ego defensen styles, and depression: A comparison of self versus informant ratings. Journal of Personality, 73, 1355-1396.

38. Folkman, S., Lazarus, R. S. (1988). The relationship betwen coping and emotion: implications for theory and research. Social Science and Medicine, 26, 309-317.

39. Galanakis, M., Stalikas, A, Kalia, H., Karagianni, C., Karela, C. (2009). Gender differences in experiencing occupational stress: the rol of age, education and marital status. Stress and Health, 25 (5), 397 - 404.

40. Greenhause, W. J., Meyer, B., Johnson, S. H. (2000). Coping and medication adherence in bipolar disorder. J Affect Disord, 59, 237-241.

41. Habra, M. A., Linden, W., Anderson, J. C., Weinberg, J. (2003). Type D personality is related to cardiovascular and neuroendocrine reactivity to acute stress. J Psychosom, 55, 235-245.

42. Hersoug, A.G., Sexton, H.C., Holglend, P. (2002). Contribution of defensive functioning to the quality of working alliance and psychotherapy outcome. American Journal of Psychotherapy, 56, 539-554.

43. Hoffart, A., Martinsen, E. W. (1993). Coping strategies in major depression, agoraphobic and comorbid in-patients: A longitudinal study. Br J Med Psychol, 66, 143-155.

44. Hoglend, P., \& Perry, J.C. (1998). Defensive functioning predicts improvement in treated major depressive episodes. Journal of Nervous and Mental Disease, 186, 238-243.

45. Ionescu, Ş. (2000). Paisprezece abordari în psihopatologie. Editura: Polirom. Iaşi. 
46. Ionescu, Ş., Jacquet, C.-L., Lhote C. (2002). Mecanismele de apărare. Teorie şi aspecte clinice. Iaşi: Editura Polirom.

47. Irimia, C. (2003). Idealizare şi Dragoste. Eseuri de psihanaliză. Editura Fundaţiei Generaţia.

48. Kennedy, B. L., Schwab, J. J., Hyde, J. A. (2001). Defense styles and personality dimensions of research subjects with anxiety and depressive disorders. Psychiatric Quarterly, 72, 251262.

49. Kessing, L. K., Agerbo, E., Mortensen, P. B. (2004). Major stressful life events and first admission with mania, 6, 122-129.

50. Kessler, R. C. (1997). The effects of stressful events on depression. Ann Rev Psychol, 48:191214.

51. Kneepkens, R. G., Oakly, L. D. (1996). Rapid improvement in the defense style of depressed women and men. Journal of Nervous and Mental Disease, 184, 358-361.

52. König, H., König, H. H., \& Konnopka, A. (2020). The excess costs of depression: A systematic review and meta-analysis. Epidemiology and Psychiatric Sciences, 29. DOI: https://doi.org/10.1017/S2045796019000180

53. Kwon, P., Lemon, K. E. (2000). Attributional style and defense mechanisms: A synthesis of cognitive and psychodynamic factors in depression. Journal of Clinical Psychology, 56, 723735 .

54. Lam, D., Scuck, N., Smith, N., Farmer, A., Checkley, S. (2003). Response style, interpersonal difficulties and social functioning in major depressive disorder. J Affect Disord, 75, 279-283.

55. Lazarus, R. S. (2000). Toward better research on stress and coping. Am Psychol, 55(6), 665673.

56. Lépine, J. P., Briley, M. (2011). The increasing burden of depression. Neuropsychiatr Dis Treat; 7:3-7. DOI: 10.2147/NDT.S19617

57. Lyubomirsky, S., Nolen - Hoeksema, S. (1995). Effect of self-focused rumination on negative thinking and interpersonal problem solving. Journal of personality and social psychology, 69, $176-190$.

58. MacGregor, M. W., Davidson, K. W., Rowan, P., Barksdale, C., Maclean, D. (2003). The use of defenses and physician health care casts: Are physician helth care costs lower in persons with more adaptive defense profiles? Psychotherapy and Psychosomatics, 72, 315-323.

59. Maricutoiu, L. P. \& Crasovan, D. I. (2016), Coping and defence mechanisms: What are we assessing? International Journal of Psychology, 51: 83-92. https://doi.org/10.1002/ijop.12113

60. McNaughton, M. E., Patterson, T. L., Irwin, M. R., Grant, I. (1992). The relationship of life adversity, social support, and coping to hospitalization with major depression. J Nerv Ment Dis, 180, 491-497.

61. McWilliams, A. L., Cox, B. J., Enns, M. W. (2003). Use of the coping inventory for stressful situations in a clinically depressed sample: Factor structure, personality correlates, and prediction of distress. J Clin Psychol, 59(4), 423-437.

62. Moos, R. H., Holahan, C. J. (2003). Dispositional and contextual perspectives on coping: toward an integrative framework. J Clin Psychol, 12, 1387-1403.

63. Moussavi, S., Chatterji, S.,Verdes, E. et al. (2007). Depression, chronic diseases, and decrements in health: results from the World Health Surveys. Lancet. 8;370:851-858. https://doi.org/10.1016/S0140-6736(07)61415-9

64. Mullen, L. S., Blanco, C., Voughn, S. C., Roose, S. P. (1999). Defense mechanisms and personality in depression. Depression and Anxiety, 10, 168-174.

65. Nasio J.-D. (1999). Conceptele fundamentale ale psihanalizei. Bucureşti: Editura Trei.

66. Nolen - Hoeksema, S. (1987). Sex differences in unipolar depression: evidence and theory. Psychol Bull, 101, 259-282.

67. Nolen - Hoeksema, S. (1991). Responses to depression and their effects on the duration of depressive episodes. Journal of abnormal psychology, 100, $569-582$.

68. Nolen - Hoeksema, S., Larson, J. (1999). Coping with loss. Mahwah, New York: Erlbaum.

69. Nolen - Hoeksema, S., Morrow, J. (1991). A prospective study of depression and distress folowing a natural disaster. The 1989 Lang Prieta eartquake. Journal of personality and social psychology, 61, $105-121$.

70. Onisei, A. B., Dumitru, C. B., \& Trifu, A. C. (2020). The psychic structure of the addict patient from a psychodynamic perspective. Journal of Educational Sciences \& Psychology, 10(2).

71. Parker, G. B., Brown, L. B. (1982). Coping behaviours that mediate between life events and depression. Arch Gen Psychiatry, 39, 1386-1391. 
72. Pedersen, S. S., Middel, B. (2005). Increased vital exhaustion among type-D patients with ischemic heart disease. J Psychosom, 51, 443-449.

73. Petraglia, J., Thygesen, K. L., Lecours, S., Drapeau, M. (2009). Diferenţe determinate de gen în mecanismele de apărare autoraportate: un studiu care utilizează noul Defense Style Questionare-60. American Journal of Psychotherapy, 63, 130-149 (traducere: Editura Trei, 2009).

74. Piccinelli, M., Wilkinson, G. (2000). Gender differences in depression: Critical review. Br J Psychiatry, 177, 486-492.

75. Porcerelli, J. H., Olson, T. R., Presniak, M. D., Markova, T., Miller, K. (2009). Defense Mechanisms and Major Depressive Disorder in African American Women. The Journal of Nervous and Mental Disease, 197 (10), 736-741.

76. Ravindran, A. V., Matheson, K., Griffiths, J., Merali, Z., Anisman, H. (2002). Stress, coping, uplifts and quality of life in subtypes of depression: a conceptual frame and emerging data. $\mathbf{J}$ Affect Disord, 71, 121-130.

77. Rosenberg, S. J., Peterson, R. A., Hayes, J. R. (1987). Coping behaviours among depressed and nondepressed medical inpatients. J Psychosom Res, 31, 653-658.

78. Rudolp, K. D., Hammen, C., Burge, D. (2000). Toward an interpersonal lifestress model of depression: The development context of stress generation. Develop Psychopath, 12,215-234.

79. Saklofske, D. H., Kelly, I. W. (1995). Coping and personality. Psychol Rep, 77, 481-482.

80. Schiffer, A. A., Pedersen, S. S., Widdershoven, J. W., Hendriks, E. H., Winter, J. B., Denollet, J. (2005). Type D personality is independently associated with impaired health status and increased depressive symptoms in chronic heart failure. Eur J Cardiovasc, 12, 341-346.

81. Schouws, S., Dekker, J., Tuynman-Qua, H., Kwakman, H., Jonghe, F. (2001). Relation between quality of life and coping and social behavior in depression. Eur J Psychiatry, 15, 4956.

82. Schuman, C., Lenz, G., Berghöfer, A., Müller-Oerlinghausen, B. (1999). Nonadherence with long-term prophylaxis: a 6-year naturalistic follow-up study of affectively ill patients. Psychiatr Res, 89, 247-257.

83. Schussler, G., Grischke, M., Ruger, U. (1992). Coping with depressive disorders. Nervenartz, 63, 416-421.

84. Sherbourne, C. D., Hayes, R. D., Wells, K. B. (1995). Personal and psychosocial risk factors for physical and mental health outcomes and course of depression among depressed patients. $J$ Consul Clin Psychol, 63, 345-355.

85. Skinner, E., A. \& Zimmer-Gembeck, M., J. (2007). The Development of Coping. Annual Review of Psychology, 58, 119-144.

86. Sommerfield, M. R., McCrae, R. R. (2000). Stress and coping research. Methodological challenges, theoretical advances and clinical applications. Am Psychol, 55, 620-625.

87. Stan, F., Drăgoi, A. M., \& Costea, R. V. (2020). The impact of socio-cultural factors in addiction comorbidities. Journal of Educational Sciences \& Psychology, 10(2).

88. Starrs, C. J and Perry, J. C (2018). Coping Action Patterns as Mechanisms of Change Across Psychotherapies: Three Case Examples of Personality Disorders With Recurrent Major Depression. Journal of Personality Disorders: Vol. 32, Mechanisms of Change in Treatments of Personality Disorders, pp. 58-74.https://doi.org/10.1521/pedi.2018.32.supp.58

89. Steiner, H., Erickson, S. J., Hernandez N. L., Pavelski, R. (2002). Coping styles as correlates of health in high school students. Journal of Adolescent Health, 30 (5), 326-335.

90. Stiemerling, D. (2006). 10 abordări psihoterapeutice ale depresiei. Bucureşti: Editura Trei.

91. Suls, J., David, J. P., Harvey, J. H. (1996). Personality and coping: three generations of research. Journal of personality, 64 (4), 711-735.

92. Suls, J., Fletcher, B. (1985). Self attention, life stress and illness: a prospective study. Psychosom Med, 47, 469-481.

93. Szadoczky, E., Rozsa, S., Zambori, J., Furedi, J. (2004). Predictors of 2-year outcome of major depressive episode. J Affect Disord, 83(1), 49-57.

94. Taylor, S. E., Stanton, A. L. (2007). Coping Resources, Coping Processes, and Mental Health. Annual Review of Clinical Psychology, 3, 377-401.

95. Uehara, T., Sakado, K., Sato, T., Someya, T. (1999). Do perceived parenting styles influence stress coping in patients with major depressive disorders? Sress and Health, 15 (3) 197-200.

96. Uehara, T., Sakado, K., Sato, T., Takizawa, R. (2002). Coping measurement and the state effect of depression and anxiety in psychiatric outpatients. Psychopathology, 35,48-51.

97. Vaillant, G.E. (2012). Lifting the Field's "Repression" of Defenses, American Journal of Psychiatry, 1699, 885-887, doi: 10.1176/appi.ajp.2012.12050703. 
98. Vaillant, G. E. (2009). The natural history of alcoholism revisited. Harvard University Press.

99. Vaillant, G. E. (2000). Adaptive mental mechanisms: Their role in a positive psychology. American Psychologist, 55(1), 89-98. doi:10.1037//0003-066X55.1.89.

100. Vaillant, G. E. (1993 a). Wisdom of the ego: Sources of resilience in adult life. Cabridge: Harvard University Press.

101. Vaillant, G. E. (1993 b). The wisdom of the ego. Cambridge: Harvard University Press.

102. Van, H. L., Dekker, J., Penn, J., Abraham, R. E., Schoevers, R. E. (2009). Valoarea predictivă a stilurilor defensive autoraportate sau evaluate de observatori în tratamentul depresiei. American Journal of Psychotherapy, 63, 42-64 (traducere: Editura Trei, 2009).

103. Walker, K., Lindner, H., Noonan, M. (2009). The Role of Coping in the Relationship Between Depression and Illness Severity in Chronic Fatigue Syndrome. Journal of Allied Health, 38 (2), 91-99.

104.Watson, D. C., Sinha, B. K. (1998). Gender, age, and cultural differences in the defense style questionnaire-40. Journal of Clinical Psychology, 54, 67-75.

105.Wilhelm, K., Parker, G. (1993). Sex differences in depressiogenic risk factors and coping strategies in a socially homogeneous group. Acta Psychiat Scand, 88, 205-211.

106.Wong, G., Lam, D. (1999). The development and validation of the coping inventory for prodomes of mania. J Affect Disord, 53, 57-65.

107.Wong, M., \& Power, T. G. (2019). Links between coping strategies and depressive symptoms among girls and boys during the transition to primary school. Early Education and Development, 30 (2), 178-195. https://doi.org/10.1080/10409289.2018.1544811

108. World Health Organization (WHO). (2011). Global burden of mental disorders and the need for a comprehensive, coordinated response from health and social sectors at the country level. EB130/9, WHO, Geneva. [Google Scholar]

109. Yamada, K., Nagayama, H., Tsutiama, K, Kitamura, T., Furukawa, T. (2003). Coping behaviour in depressed patients: a longitudinal study. Psychiatry Res, 121, 169-177. 